\title{
Aspectos importantes que se debe saber sobre la Pensión de vejez
}

\author{
Saúl López Montiel ${ }^{1}$
}

\section{Introducción a la pensiones en México}

Dice un popular refrán que "nadie escarmienta en cabeza ajena", pensamiento que se viene a la cabeza, cuando existe el tema de las pensiones, ya que casi nadie piensa, cuando aún estamos jóvenes, en que inevitablemente nos haremos viejos, si acaso llegamos, claro. Lo anterior, lo digo, porque vemos que mucha gente cuando ya no está en condiciones para trabajar por su edad, se convierte en una carga económica para su familia. Como nos gustaría, que todos pensáramos y actuáramos en el presente, en como planear nuestra forma de subsistir en la vejez, haciendo lo que esté en nuestras manos y buscando el menor costo posible, en su caso.

En México, cada año que pasa se incrementa el número de personas con edad para exigir una pensión por vejez o cesantía en edad avanzada, debido a que va en aumento la edad promedio de la población, lo que seguramente en un futuro generará diversos problemas a nuestro Sistema de Pensiones. Lo anterior podría complicarse aún más si consideramos que también hay un incremento en el nivel promedio de vida de las personas, lo que originará una mayor demanda en los servicios médicos y hospitalarios.
Haciendo un poco de historia, recordemos que en 1997 entró en vigor una nueva Ley del Seguro Social, cuya principal modificación fue en el tema de la pensión, con el objetivo de salvaguardar el bienestar de la población en edad de retiro. Estos cambios fueron principalmente en desligar al Instituto Mexicano del Seguro Social (IMSS) de la responsabilidad de la determinación y pago de la pensión, ya que este organismo era el encargado de la administración de las pensiones a través de una cuenta colectiva, la cual funcionaba con la recaudación que se hacía sobre el salario de los trabajadores activos, financiando de esta manera las pensiones de los trabajadores inactivos. El otro gran cambio fue la creación de las Administradoras de Fondos para el Retiro (afores), instituciones financieras que se encargarían de administrar e invertir el ahorro para el retiro de los trabajadores afiliados al IMSS. A partir de ese año, el IMSS sólo se encarga de exigir, recolectar y posteriormente transferir los recursos a las afores. 


\section{Que son y cómo se determinan las pensiones}

Antes de ver como se determinan las pensiones, se debe tener claro algunos concepto del tema, de los cuales, después de una búsqueda de varios autores y artículos, se pueden sintetizarlo en los siguientes:

¿Qué es una pensión? Es el pago periódico (vitalicio o programado), que recibe una persona que ya no está en posibilidades de trabajar y cumple con los requisitos establecidos en la Ley del Seguro Social. (Fracción III del Art. 159 LSS)

¿Qué es la Cesantía en Edad Avanzada? Según la Ley del Seguro Social, existe cesantía cuando un asegurado queda privado de trabajos remunerados a partir de los sesenta años de edad. (Art. 154 LSS)

¿Qué es la Vejez? Es la inevitable consecuencia del paso del tiempo en un individuo y para la Ley del Seguro Social, esta etapa llega a los sesenta y cinco años de edad (Art. 162 LSS)

Renta vitalicia, el contrato por el cual la aseguradora a cambio de recibir los recursos acumulados en la cuenta individual se obliga a pagar periódicamente una pensión durante la vida del pensionado (Fracc. IV Art. 159 LSS)

Retiros programados, la modalidad de obtener una pensión fraccionando el monto total de los recursos de la cuenta individual, para lo cual se tomará en cuenta la esperanza de vida de los pensionados, así como los rendimientos previsibles de los saldos (Fracc. V Art. 159 LSS)

Pensión garantizada es aquélla que el Estado asegura a quienes reúnan los requisitos señalados en la Ley del Seguro Social y su monto mensual será el equivalente a un salario mínimo (Art. 170 LSS)
Seguro de sobrevivencia, aquél que se contrata por los pensionados, con cargo a a favor de sus beneficiarios para otorgarles la pensión, ayudas asistenciales y demás prestaciones en dinero, mediante la renta que se les asignará después del fallecimiento del pensionado, hasta la extinción legal de las pensiones. (Fracc. VI Art. 159 LSS)

Se ha comentado que derivado de la modificación a la Ley del Seguro Social en 1997, en el tema de pensiones, se en la Ley de 1973 (refiriéndose a la que estuvo vigente hasta julio de 1997) y la Ley de 1997 (ley vigente), de las cuales se puede resumir los principales requisitos para obtener una pensión:

Principales requisitos para obtener una pensión.

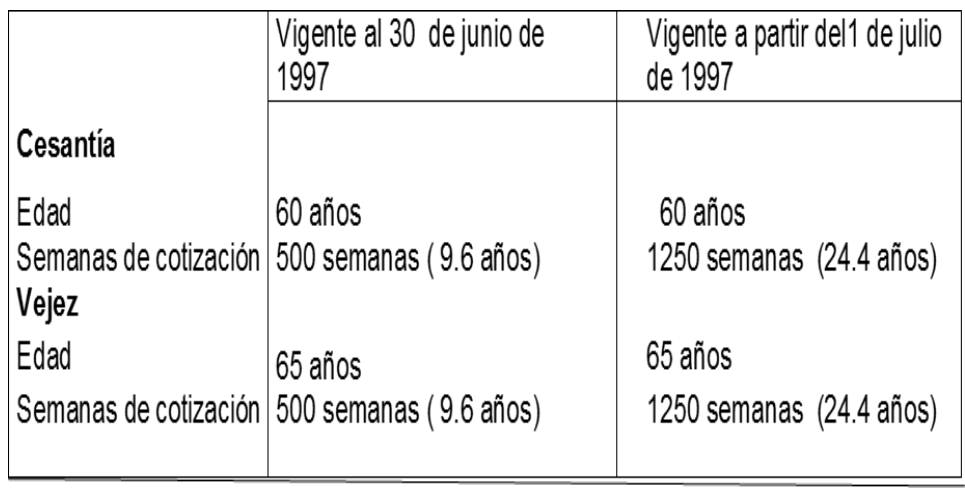

Fuente: Elaboración propia

En la nueva Ley del Seguro Social, en el Artículo Tercero Transitorio, se establece que todos aquellos trabajadores que hayan sido inscritos con anterioridad al primero de julio de 1997, tendrán, al momento de cumplir con los requisitos de pensionarse, el derecho de elegir entre la Ley anterior del año de 1973, y la Ley actual del primero de julio de 1997, lo que más beneficie a sus intereses.

De acuerdo a la experiencia en los diversos trámites efectuados, la mejor opción para las personas que están por pensionarse es ejercer el derecho que otorga este Artículo Tercero transitorio, y retirarse bajo las condiciones establecidas por la Ley de 1973, porque, de acuerdo con la Ley que sé derogó, las condiciones para una pensión por Cesantía en Edad Avanzada y vejez son menores en cuanto a las semanas cotizadas y en cuanto al monto a pagar entre ambas Leyes 


\section{Apéndices Técnicos}

- Tienen derecho a una pensión.

- Prestaciones en especie del Seguro de Enfermedades y maternidad (atención médica, farmacéutica y hospitalaria para el pensionado y sus beneficiarios legales).

- Asignaciones familiares.

- Ayuda asistencial.

- Al momento de pensionarse, se tiene derecho a:

A) Recibir en una sola exhibición los fondos acumulados en la subcuenta de vivienda (aportaciones previas a 1992 el doble sin intereses, aportaciones entre 1992 y 1997 con intereses generados). Se deberá tramitarse en el INFONAVIT.

B) Pago en una sola exhibición del monto acumulado por concepto del $2 \%$ del SAR y los rendimientos que se hubieren generado, desde 1992 hasta la fecha de la pensión (art. 164 LSS)

Si se pensiona con la Ley de 1997, de conformidad con el artículo 164 de la Ley del seguro Social, se tienen las siguientes opciones:

- Contratar con la Institución de seguros que elija, una Renta Vitalicia, la cual obtendrá cuando la aseguradora, a cambio de recibir los recursos acumulados en la cuenta individual, se obliga a pagar periódicamente una pensión durante la vida del pensionado, o bien.

- Retiros Programados que es la modalidad de obtener una pensión fraccionando el monto total de los recursos de la cuenta individual, para la cual se tomará en cuenta la esperanza de vida de los pensionados, así como los rendimientos previsibles de los saldos.
- Independientemente de la opción seleccionada, deberá contratar un seguro de sobrevivencia; es el que contratan los pensionados, por: Riesgo de Trabajo, Invalidez, Cesantía en Edad Avanzada o Vejez, con cargo a los recursos de la suma asegurada, adicionados a los recursos de la cuenta individual a favor de sus beneficiarios; servirá para otorgarles la pensión, ayudas asistenciales y demás prestaciones en dinero previstas en los respectivos seguros, mediante la renta que se le asignará después del fallecimiento del pensionado y hasta la extinción legal de las pensiones.

Una de las situaciones que se presenta en la determinación de las pensiones, se deriva cuando el asegurado cumple con el requisito de la edad, pero no reúne las semanas de cotización antes señaladas, dentro de lo cual el pensionado podrá retirar el saldo de su cuenta individual en una sola exhibición o seguir cotizando hasta cubrir las semanas necesarias para que cubra su pensión. Si el asegurado tiene cotizado un mínimo de setecientas cincuenta semanas tendrá derecho únicamente a las prestaciones en especie del Seguro de Enfermedades y Maternidad (atención médica, quirúrgica, farmacéutica y hospitalaria) para él y sus beneficiarios legales.

Actualmente, se ha revivido el tema de la forma en determinar el monto de la pensión, tratándose de trabajadores que se pensionaron o se pensionaran bajo la Ley de 1973, denominado "régimen de transición", ya que los tribunales han emitido en fechas recientes el criterio que para determinar el monto máximo de la pensión, se debe considerar el tope de cotización que existía en la ley de 1973, es decir, determinar un monto máximo de 10 veces el salario mínimo, y no de los 25 veces el salario mínimos que rigen actualmente. La tesis jurisprudencial es la siguiente: 
PENSIÓN POR CESANTÍA EN EDAD AVANZADA. AL RESOLVER LA JUNTA SOBRE EL AJUSTE EN LA CUANTIFICACIÓN DE SU PAGO, DEBE ATENDER EL LÍMITE SUPERIOR PREVISTO EN EL PÁRRAFO SEGUNDO DEL ARTÍCULO 33 DE LA LEY DEL SEGURO SOCIAL, VIGENTE HASTA EL 30 DE JUNIO DE 1997, SIN QUE REPRESENTE OBSTÁCULO ALGUNO QUE EL DEMANDADO NO SE HUBIERE EXCEPCIONADO EN ESE SENTIDO, publicada en el Semanario Judicial de la Federación y su Gaceta, Décima Época, Libro 27, Tomo I, p. 913, materia Laboral, Tesis 2a./J. 8/2016 (10a.), Jurisprudencia, Registro 2010989, febrero de 2016.

En este criterio la Corte señaló que no puede variarse la manera en que deben cubrirse las prestaciones descritas en la LSS'73 (límite de 10 veces el salario mínimo), pues se trata de una disposición de orden público y de observancia obligatoria.

Dicho criterio de la Corte, tiene como antecedente este otro de 2010, que básicamente decía lo mismo:

SEGURO SOCIAL. EL SALARIO PROMEDIO DE LAS ÚLTIMAS 250 SEMANAS DE COTIZACIÓN, BASE PARA CUANTIFICAR LAS PENSIONES POR INVALIDEZ, VEJEZ Y CESANTÍA EN EDAD AVANZADA, TIENE COMO LÍMITE SUPERIOR EL EQUIVALENTE A 10 VECES EL SALARIO MÍNIMO GENERAL VIGENTE EN EL DISTRITO FEDERAL, ACORDE CON EL SEGUNDO PÁRRAFO DEL ARTÍCULO 33 DE LA LEY RELATIVA, VIGENTE HASTA EL 30 DE JUNIO DE 1997, publicada en el Semanario Judicial de la Federación y su Gaceta, Novena Época, Tomo XXXII, p. 311, materia laboral, Tesis 2a./J. 85/2010, Jurisprudencia, Registro 164218, julio de 2010, en donde precisó que el límite de 10 veces el salario mínimo general debe aplicarse para el cálculo de las pensiones de CEAV pues dichas ramas se encontraban financiadas con ese tope de SBC, por lo que no se puede dar un beneficio mayor si su base de cotización era diferente.
Como podrá apreciarse, el criterio de la Corte tiene su base jurídica para una posible aplicación por parte de las autoridades del Seguro Social, con lo cual se impactarían en forma muy importante el monte a recibir de muchos pensionados; sin embargo, las propias autoridades del IMSS han declarado, en voz su director general, Sr. Mikel Arriola Peñaloza, en entrevista con Excélsior, expreso que el IMSS no modificará el modelo de cálculo de las pensiones y las seguirá pagando con un tope 25 veces el salario mínimo vigente.

Según cálculos de la Comisión Nacional del Sistema de Ahorro para el Retiro (CONSAR) el costo total de pagar las pensiones de los 1.32 millones de trabajadores de la generación de transición, con un tope de 25 veces el salario mínimo, es de siete billones 753 mil 73 millones de pesos. Si las pensiones de estos trabajadores se pagaran con un tope de 10 salarios mínimos, como la Suprema Corte de Justicia de la Nación lo establece en una jurisprudencia relativa a este tema, el costo para instituto de seguridad social sería de cinco billones 101 mil 45 millones de pesos.

La diferencia entre ambas cantidades corresponde al costo fiscal de mantener el tope salarial de 25 salarios mínimos, que suma dos billones 652 mil 28 millones de pesos, lo que es equivalente a $99.8 \%$ del total de los recursos acumulados en el Sistema de Ahorro para el Retiro; casi $14 \%$ del Producto Interno Bruto.

En caso de las autoridades decidan aplicar dichos criterios, se deben considera los siguientes puntos:

1. Los trabajadores que deciden pensionarse en el régimen de la Ley de 1973, también cotizaron bajo el amparo de la Ley de 1997, es decir cubrieron sus cuotas con un ingreso superior 10 veces al salario mínimo, esto es con el tope de 25 veces. 


\section{Apéndices Técnicos}

2. Lo establecido en el artículo 14 primer párrafo de la Carta Magna, en cuanto a que a ninguna ley se le puede dar efecto retroactivo en perjuicio de persona alguna, por lo tanto el juzgador debe aplicar la ley que más favorezca al asegurado.

3. El tope de 25 veces el salario para efectos pensionarios no va en contra de las finanzas del IMSS, pues los solicitantes cotizaron con esa base, por tanto su pensión es en proporción a lo que pagaron de cuotas. El cálculo de las pensiones de los trabajadores topados para la cuantía básica debe considerarse el salario promedio de las últimas 250 semanas de cotización, tomando en cuenta el tope salarial con el que realmente hubiesen pagado sus cuotas (Art. 167, Ley de 1973).

4. Considerar el tope de 10 veces el salario mínimo para el cálculo de las pensiones provocaría que los trabajadores afectados soliciten al Seguro Social la devolución de las cuotas pagadas en demasía (las que rebasen el límite salarial aplicado), derecho que también podría ser ejercido por los patrones de aquellos.

5. En términos del artículo 36 del Código Fiscal de la Federación, el IMSS podría promover juicios de lesividad para anular sus propias resoluciones en donde otorgó pensiones con un Salario Base de Cotización como límite superior de 25 veces el salario mínimo, lo cual a todas luces generaría una incertidumbre jurídica en los pensionados en dichas condiciones

\section{Conclusión:}

El tema de pensiones, debe ser algo que preocupe y ocupe a todos, si somos personas que actualmente estamos generando nuestros ingresos sin tener una relación laboral, hay que tomar en cuenta que las cosas pueden cambiar, quienes piensan que hacer un capital para con el subsistir en la vejez, es válido, pero también conlleva un riesgo, por lo que no está demás, el poder tener un ingreso más seguro en esa etapa de nuestra vida, además con un costo que ya incurrimos, y dejándole un ingreso un tanto más seguro a nuestros beneficiarios.

\section{Bibliografía:}

Ley del Seguro Social, CÁMARA de Diputados del H. ConGRESO DE LA UNIÓN

Secretaría General, Secretaría de Servicios Parlamentarios, Última Reforma DOF 12-11-2015

Periódico Excélsior, 17 de mayo de 2016, sección Nacional Semanario Judicial de la Federación y su Gaceta, Novena Época, Tomo XXXII

\section{8 / Trascender, Contabilidad y Gestión}

